\title{
"Deus está nos detalhes": percorrendo imagens de medos, reverências e terror
}

\author{
Luciana da Costa de Oliveira*
}

Pontifícia Universidade Católica do Rio Grande do Sul, Porto Alegre - RS, Brasil

Ginzburg, Carlo. Medo, reverência e terror. Quatro ensaios sobre iconografia política. São Paulo: Companhia das Letras, 2014.

"Deus está nos detalhes", costumava dizer Aby Warburg diante das imagens. E da mesma forma que o intelectual alemão, o historiador italiano Carlo Ginzburg, desde muito tempo, vem trilhando semelhante caminho. Inicialmente, a partir de processos inquisitoriais, ele trabalhou elementos precisos do que se consagrou como micro-história. Anos depois, com tal arcabouço teórico bastante fundamentado, incursionou pelo estudo da arte onde, em Investigando Piero, articulou as obras de Piero della Francesca junto a uma ampla rede de relaçóes e significaçôes. E é precisamente nesse ponto, onde detalhes e particularidades da imagem emergem, que Ginzburg aproxima-se do viés analítico warburguiano.

A proximidade - e as relações - que o historiador estabeleceu não só com a arte, mas especialmente com os conceitos e métodos de Aby Warburg, não são recentes. Desde a década de 1960, quando pela primeira vez realizou estudos no Instituto Warburg e aproximou-se dos intelectuais ligados a tal instituição, especialmente com historiador da arte Ernst Gombrich, Ginzburg associou o estudo da imagem junto aos diversos elementos que estavam em seu entorno. Assim, quando tem por objeto de pesquisa as fontes visuais, ele as coloca como o centro de uma teia onde os diversos fios são tecidos, principalmente, pelas relaçóes que a obra estabelece com o contexto, com o artista (e seus referenciais), com os círculos intelectuais e com os processos de circulação e recepção.

Dessarte, pensando e problematizando a imagem a partir de suas múltiplas possibilidades, é que o autor apresenta Medo, reverência e terror: quatro ensaios de iconografia política. Como o próprio título já anuncia, a obra em questáo é constituída pela reuniáo de quatro ensaios. Publicados em diferentes momentos, ambos foram apresentados pelo autor em palestras e aulas de distintas universidades europeias e americanas. E mesmo que o mais antigo deles remonte ao ano de 1999, a reunião e tradução de todos foi realizada, no Brasil, apenas em 2014.

Os textos do historiador apresentam temáticas, obras e períodos diferenciados. No entanto, possuem como fio condutor o conceito warburguiano de Pathosformeln. Entendido, também, como a memória dos

* Doutoranda em História pela PUCRS e gestora editorial da revista Estudos Ibero-Americanos (PUCRS). E-mail: luciana_de_oliveira@hotmail.com. 
gestos, ${ }^{1}$ o autor referencia tal formulação já na introdução do livro, partindo de um texto bastante conhecido de Aby Warburg: Dürer e a Antiguidade Italiana. Neste estudo, as imagens relativas à morte de Orfeu que aparecem tanto em um desenho de Dürer quanto em uma gravura proveniente do círculo de Mantegna, ambas do século $\mathrm{XV}$, estabelecem relações próximas com a gestualidade expressiva encontrada em vasos da antiguidade greco-romana. Segundo Warburg, "a Morte de Orfeu oferece um ponto de partida seguro para se chegar, por várias direçôes, à compreensão dessa corrente patética contida na influência da Antiguidade redesperta". ${ }^{2}$ Nessa perspectiva, os gestos e movimentos do Orfeu renascentista teriam sido recuperados, de forma intensificada, da Antiguidade clássica.

Essa intensificação dos movimentos, no entanto, não pode ser percebida, apenas, como cópia dos gestos gregos. A ambivalência que perpassa não só a elaboração de tais produçōes pictóricas, mas igualmente o tempo anacrônico que as conectam em diferentes momentos, é de fundamental importância para a compreensão não só das imagens mas, também, do conceito de Pathosformeln. Para Warburg, quando tais gestos sobrevivem, quando eles ressurgem de maneira fantasmal em imagens renascentis-

\footnotetext{
${ }^{1}$ DIDI-HUBERMAN, Georges. A imagem sobrevivente. História da arte e tempo dos fantasmas segundo Aby Warburg. Rio de Janeiro: Contraponto, 2013, p. 193.

${ }^{2}$ WARBURG, Aby. Dürer e a Antiguidade italiana. In.: WAIZBORT, Leopoldo. História de fantasmas para gente grande - Aby Warburg. Escritos, esboços e conferências. Sáo Paulo: Companhia das Letras, 2015, p. 90.
}

tas, observa-se, muitas vezes, uma inversão em seu sentido.

Comentando um estudo empreendido pelo intelectual alemão e que foi retomado por Edgard Wind posteriormente, Ginzburg evidencia onde essa inversão se manifesta. Citando o caso de Maria Madalena e das bacantes da Antiguidade, um conjunto de semelhantes gestos expressivos era constatado. No entanto, mesmo que demonstrassem emoçôes extremas, suas funçôes e sentidos eram completamente opostos. Por tal razão é que a memória dos gestos torna-se, também, fundamental para esse processo de análise imagética.

As observações realizadas por Aby Warburg acerca de tais questóes foram materializadas em seu Atlas Mnemosyne. Projeto de grande fôlego e que ficou inacabado, objetivava apresentar as sobrevivências (Nachleben) das imagens e, assim, evidenciar a forma com a qual os gestos semelhantes podiam assumir significados diferentes e opostos. Além disso, o conceito de engrama, ou a memória primitiva dos movimentos, igualmente encontrava ressonância nesse amplo conjunto que visava perceber náo apenas essas transmissóes mas, sobretudo, a forma como transitavam no tempo.

Percorrendo direção semelhante, especialmente no que se refere às sobrevivências e memória dos gestos e emoçóes, é que Ginzburg vai trabalhar, além de pinturas consagradas como Marat em seu último suspiro e Guernica, o frontispício (O Leviatã) e a fórmula de ideias que serviram de base para as formulações filosóficas e políticas de Thomas Hobbes e, igualmente, um cartaz 
do Exército Britânico que conclamava os jovens para a guerra. Mesmo que tais trabalhos possuam especificidades temporais, a maneira como o historiador faz dialogar política e arte junto aos medos e terrores encontra no Pathosformeln o seu ponto de encontro.

$\mathrm{O}$ primeiro ensaio apresentado pelo autor e que, de certa forma, é introdutório tanto aos conceitos trabalhados ao longo da obra quanto à metodologia proposta e fundamentada no pathosformeln de Aby Warburg centra-se na atualidade de Thomas Hobbes. Partindo de questóes do presente, especialmente no período que se seguiu ao 11 de setembro, o historiador faz seu leitor andarilhar um duplo caminho: o da trajetória pessoal e intelectual do filósofo inglês e o de suas percepçôes acerca da noção e da ação do medo na origem da religião e do Estado.

Para tanto, através de um encadeamento de ideias, palavras, obras e tempos, Giznburg desvela, a partir do uso que Hobbes faz do termo to awe - tomado da tradução de A guerra do Peloponeso, de Tucídides - uma gama de inter-relaçôes. Perscrutando a origem da expressão, o autor trabalha com a noção de Logosformal, ou seja, a fórmula de ideias. Estas, conforme se pode acompanhar no decorrer do texto, se fazem presentes nos diferentes frontispícios de O Leviatã, onde as noçóes de medo, terror e reverência são postas em evidência. Elas relacionam-se, também, com os elementos religiosos ligados a tais emoçóes e que perpassaram a filosofia política de Hobbes. Nesse sentido, a secularização da política proposta pelo filósofo teria, em úl- tima instância, uma relação bastante próxima com elementos e sentimentos suscitados pela religiáo.

No segundo ensaio, dedicado à obra Marat em seu último suspiro, de Jacques-Louis David, são apresentados ao leitor os inúmeros entrelaçamentos e perspectivas utilizadas — e vivenciadas — pelo artista na elaboração de sua pintura. Mesmo comentando no início do texto que o Marat foi amplamente estudado, os elementos buscados por Ginzburg trilham e aprofundam outros itinerários.

Com isso, buscando referenciais em textos e imagens diferenciados, o autor estabelece um diálogo não só entre Jacques-Louis David, a Revolução Francesa e a pintura mas, igualmente, entre política, secularização e religião. Os elementos que utiliza para tal análise, muito mais amplo que os estudos anteriores, também contemplam a mescla de memórias e tempos provindos da Antiguidade e do cristianismo.

O penúltimo texto que compóe a obra, denominado "Seu país precisa de você: um estudo de caso em iconografia política”, é onde o conceito de Pathosformeln é mais profundamente trabalhado. Analisando a construção do cartaz que incitava os jovens ingleses a comporem os batalhóes para a Primeira Guerra Mundial, onde a figura de Lord Kitchener assumiu importância central, Carlo Ginzburg estuda a forma com a qual tanto o histórico do militar inglês foi relevante para essa produção quanto como determinados gestos e movimentos foram utilizados para que o cartaz tivesse a eficácia desejada pelo Exército. 
O autor elabora a sua tessitura de ideias partindo do olhar e do dedo que aponta Lord Kitchener aos observadores do cartaz. Buscando subsídios — e sobrevivências — nos escritos de Plínio, quando este descrevia a elaboração de uma estátua de Alexandre, o Grande, o historiador italiano evidencia como, a partir de representaçóes de Cristo, textos medievais e imagens da Antiguidade, tais olhares e gestos já estavam presentes e desempenhavam importantes funções, especialmente quando se objetivava prender a atenção do público ao qual tais imagens eram direcionadas. Eram, em última análise, chamados e chamamentos anacrônicos.

Assim, é a partir desse entrelaçamento de fios, imagens e tempos que as noçôes de Pathosformeln são apresentadas. Era na memória do gesto incisivo do dedo e na do olhar que a todos vigiava que repousava a função primeva desse tipo de produção: intimar e chamar o observador. Influenciando outros cartazes do gênero e que seguiam o mesmo objetivo, Carlo Ginzburg ainda aponta para a relevância da publicidade e a relação próxima que ela estabeleceu com essas produçóes.

É precisamente nesse ponto, ainda, que a questão da inversão do significado do gesto, tal qual as bacantes e a Maria Madalena estudada por Warburg, é trabalhada pelo autor. No caso dos cartazes publicitários, ele pontua que o chamamento utilizado no cartaz de Lord Kitchener foi reutilizado com sentido comercial e de consumo. Ambos apontam dedos e quase intimidam seus observadores com o olhar. São, sem dúvidas, chamados. Porém, utilizados de formas diferentes e que acabam, também, por ter significados e eficácias diversos.

Finalizando a obra, o último ensaio apresentado por Ginzburg retoma Guernica, de Pablo Picasso, a partir de outro viés interpretativo. Tendo por suporte as especificidades da obra, como as percepçóes do artista, o contexto em que foi produzida e o debate artístico travado no período, especialmente o que relacionava o modernismo às democracias liberais e o classicismo aos regimes totalitários, são problematizados os entornos da pintura em si e, mais especialmente, os elementos que mais profundamente serviram de base para Picasso.

Ao iniciar o ensaio com uma fala do artista, onde este diz ser fundamental, para o conhecimento de uma obra, saber quando o artista a "fez, por que, como, em que circunstância (...)", Ginzburg estabelece a rede de relaçóes que contempla todos esses elementos. Explorando o caminho dos esboços que o artista fez para Guernica, o autor percebe não apenas as metamorfoses pelas quais a pintura passou mas, sobretudo, as confluências entre elementos da antiguidade e da modernidade presentes na pintura.

Assim, Guernica não se constitui, apenas, como uma obra alusiva à Guerra Civil Espanhola. Sem dúvidas, seu contexto de produção foi o do conflito. Mas os entremeios de sua produção estiveram ligados tanto às inquietaçóes do próprio artista, ao debate intelectual e artístico do período e, igualmente, ao amplo referencial imagético que Picasso detinha (seja ele o de seus contemporâneos ou o de suas memórias). 
Os quatro ensaios de Carlo Ginzburg são, em última análise, escritos de fôlego e erudição. Mas, mais que isso, denotam novas possibilidades de se trabalhar as fontes visuais. Partindo de obras como Marat em seu último suspiro e Guernica, ambas de amplo conhecimento, os estudos não se centram, apenas, na relação fechada entre obra e contexto ou em seus aspectos formais. Tampouco as considera como expressão única de uma época. Ultrapassando tais análises reducionistas, que não consideraram os elementos específicos e particulares das imagens, o autor as insere como elementos de provocação - e perturbação - de conhecimentos e saberes por muito estabelecidos. A partir do momento em que o artista, a obra e o contexto dialogam com outros tempos, imagens e textos, a sua análise e percepção, certamente, reveste-se e, igualmente, proporciona novas significaçóes.

Tal viés interpretativo, que tomou forma a partir dos estudos empreendidos por Aby Warburg em fins do século XIX, foi de grande importância para esse novo olhar que mais demorada e detalhadamente se coloca sobre as imagens. Apesar de, ainda hoje, muitas dessas fontes serem tratadas apenas como ilustraçóes ou, ainda, como conclusões visuais de textos escritos, o fato é que as análises realizadas têm se aproximado cada vez mais de metodologias que percebem a imagem a partir de sua ampla gama de possibilidades e, igualmente, de seu viés antropológico.

Nesse sentido, compreender que as imagens pensam e que, da mesma forma, são portadoras de memórias de tempos diferentes entre si, permite a abertura de um leque de possibilidades interpretativas e, também, a tessitura e emergência de novos conhecimentos. Tal foi o caso, por exemplo, de Aby Warburg quando empreendeu o seu mais grandioso projeto através das pranchetas pretas e das imagens em branco e preto de seu Atlas Mnemosyne.

Por fim, muitos entrecruzamentos são percebidos entre Warburg e Ginzburg. Mesmo que o autor tenha sublinhado o uso dos conceitos elaborados pelo intelectual alemão, outras reminiscências — e sobrevivências - também surgem dos textos que compóe Medo, reverência e terror. De forma semelhante às ninfas de Botticelli, que foram observadas e analisadas por Warburg a partir de suas especificidades mais precisas, Ginzburg também é provocado e instigado pelo detalhe. Não é por acaso que uma expressão específica, utilizada por Thomas Hobbes na tradução de Tucídides, torna-se o eixo da análise de uma Logosformal. Ou que particularismos imagéticos, como a data colocada por David em seu Marat e, também, a constante metamorfose das formas utilizadas por Picasso em Guernica, apontem elementos muito maiores e mais abrangentes que a pintura. Mas também quando gestos e olhares são percebidos junto a uma ampla gama de referenciais de outros tempos e memórias, parece que Deus, aquele que Warburg dizia encontrar nos detalhes, finalmente torna-se visível e compreensível na confluência de todos esses elementos. 